\title{
Adjuvant radiochemotherapy in locally advanced gastric cancer: from evidence to daily clinical practice in a single institution
}

\author{
Manuel González-Domingo ${ }^{1}$, Cristóbal Ulloa ${ }^{2}$, Jorge Olivares ${ }^{3}$, Sebastián Estrada², Pablo González ${ }^{4}$ and Neyla Cardozo ${ }^{1}$ \\ ${ }^{1}$ Department of Radiation Oncology, Instituto Oncológico, Viña del Mar, 2540364, Chile \\ ${ }^{2}$ Surgery resident, University of Valparaíso, Chile \\ ${ }^{3}$ Oncology and Radiotherapy resident, University of Valparaíso, Chile \\ ${ }^{4}$ Department of Radiation Oncology, Arturo López Pérez Foundation, Santiago, Chile
}

\section{Abstract}

Background: Gastric cancer is one of the main important causes of cancer death in Chile.

Objective: To report the results of adjuvant radiochemotherapy in advanced gastric cancer.

Material and Methods: Between 2000 and 2018, 214 subjects aged 23-85 (median, 62) years with lymph node and/or serosa involvement were treated with adjuvant chemoradiotherapy after curative resection.

Results: With a median follow-up of 41 months, overall 3- and 5-year survival was 54.9\% and $40.85 \%$, respectively. On multivariate analysis, the factors associated with lower survival were aged $>65$ years, stage group and number of lymph nodes involved.

Conclusion: In patients with locoregionally advanced gastric cancer treated with curative intent with surgery and adjuvant radiochemotherapy, the overall 5-year survival reported from local clinical practice is similar to that reported in randomised series and supports its use as an effective treatment for this type of patients in our country.

Keywords: gastric cancer, radiotherapy, overall survival, radiochemotherapy, clinical practice

\section{Introduction}

The incidence of gastric cancer worldwide for 2018 was 15.7 per 100,000 inhabitants [1].

Gastric cancer ranks third after lung and liver cancers for low- and middle-income countries. Chile is among the countries with the highest incidence rates, along with Japan, Costa Rica and Singapore [1].

When analysing Chile's national epidemiology, the incidence of gastric cancer in men is 29.7 per 100,000 inhabitants, being second only to prostate cancer. On the contrary, it is in the fifth place for women, with an incidence rate of 14.3 per 100,000 inhabitants, after breast, non-melanoma skin, gallbladder, biliary tract and cervix cancers [2].

When analysing the specific causes of mortality by the type of cancer and sex in 2015 , we found that the main causes of death in men were gastric cancer, with 2,247 deaths

Correspondence to: Manuel González-Domingo Email: mgonzalez@institutooncologico.cl

ecancer 2020, 14:1137

https://doi.org/10.3332/ecancer.2020.1137

Published: 05/11/2020

Received: 21/07/2020

Publication costs for this article were supported by ecancer (UK Charity number 1176307).

Copyright: $($ ) the authors; licensee ecancermedicalscience. This is an Open Access article distributed under the terms of the Creative Commons Attribution License (http:// creativecommons.org/licenses/by/3.0), which permits unrestricted use, distribution, and reproduction in any medium, provided the original work is properly cited. 
(25.2 per 100,000 inhabitants), followed by prostate cancer, while gastric cancer was in the fourth place for women, with a rate of 12.3 per 100,000 inhabitants after breast and lung cancers [3].

In the Valparaíso Region, the adjusted regional mortality rate exceeds the national one for men, with 29.8 per 100,000 inhabitants [3].

Radical (RO) surgical resection is the standard surgical treatment for gastric cancer. Subtotal or total gastrectomy with D2 lymph node dissection is recommended in patients with regionally advanced gastric cancer [5]. However, for stage-II and -III diseases [4], surgery alone is not sufficient for cure.

The 5-year survival rate decreases rapidly with the increase of the disease stage. Among western patients with localised lesions, the 5-year survival rate is $65 \%$; however, for those with regional spread, the estimated 5 -year survival is reduced to $30 \%$ (6.7). This poor prognosis among resected patients promoted the development of several studies that supported adjuvant strategies.

The purpose of our study is to evaluate the results of adjuvant radiochemotherapy for gastric cancer patients undergoing surgery with curative intent in clinical practice at our institution and to compare their results with those published to date.

\section{Materials and methods}

The study presents a retrospective cohort of all patients diagnosed with locally advanced gastric cancer (T1-4, N1-3, M0) who received surgery plus fluoropyrimidine-based adjuvant radiochemotherapy with curative intent between 2000 and 2018 at the Viña del Mar Cancer Institute; follow up was adjourned to March 2020. All patients underwent surgery at different centres in the $\mathrm{V}$ region and were referred to the Cancer Institute. Two-hundred and 14 patients received adjuvant radiochemotherapy, of whom 60 (28\%) were women and 154 (72\%) men. The median age was 62 years (range 85-23 years). In 12 patients (5.6\%), the tumour invaded to the submucosa; in 24 (11\%), it reached the muscularis propria; in 44 (20.5\%), it penetrated the subserosa without invasion of the visceral peritoneum and in 134 (63\%), the tumour invaded the serosa. Eighty-five per cent of the patients had lymph node involvement and one-third of them had seven or more involved nodes. T and $\mathrm{N}$ stage distribution and disease stages are presented in Table 1 . The average number of lymph nodes examined was 22 . Of the 214 patients, $60.7 \%$ had $>16$ lymph nodes studied and only in 29 patients were $<10$ lymph nodes studied.

All patients were treated with a three-dimensional conformational technique by a high-energy dual-linear accelerator (6-10 MV), receiving a dose of 45 Gy in 25 fractions on the bed, regional nodes and anastomosis or a total-abdomen radiotherapy (WAI) regimen, according to the GOCCHI RATONES study [8]. Chemotherapy was fluoropyrimidine-based, and the most used regimen was daily oral capecitabine. Patients' characteristics are presented in Table 2.

All patients were staged according to the classification of the American Joint Committee on Cancer (AJCC) 8th Edition [4].

Survival analysis was performed using the Kaplan-Meier method, and survival data were obtained from the Chilean Civil Registry. The logrank method was used for comparisons of survival between groups. All analyses were performed by STATA 16.

Table 1. Distribution between T, N and stage according to AJCC 8th ed. [4]

\begin{tabular}{|l|c|c|c|c|c|c|}
\hline & pN0 & pN1 & pN2 & pN3a & pN3b & Total (\%) \\
\hline pT1 & 0 & 8 & 3 & 1 & 0 & $12(5.6)$ \\
\hline pT2 & 2 & 11 & 8 & 2 & 1 & $24(11.2)$ \\
\hline pT3 & 14 & 6 & 13 & 6 & 5 & $44(20.5)$ \\
\hline pT4a & 16 & 19 & 43 & 37 & 19 & $134(62.6)$ \\
\hline Total (\%) & $32(14.9)$ & $44(20.5)$ & $67(31.3)$ & $46(21.5)$ & $25(11.6)$ & $214(100)$ \\
\hline
\end{tabular}

Stage: II-A
II-B

III 


\section{Results}

With a median follow-up of 41 months for the entire group (123 months for living patients), the overall survival at 3 and 5 years for the entire group was $54.9 \%$ and $40.85 \%$, respectively (Figure 1). Overall 5 -year survival according to sex was $46 \%$ in females and $37 \%$ in males ( $p=0.08$ ).

Table 2. Patient, treatment and tumour-related characteristics.

\begin{tabular}{|c|c|c|}
\hline & $\mathrm{N}^{\circ}$ patients $(214)$ & $\%(100)$ \\
\hline $\begin{array}{l}\text { Age } \\
\text { Median } \\
\text { Range }\end{array}$ & \multicolumn{2}{|c|}{$\begin{array}{c}62 \\
(23-85)\end{array}$} \\
\hline $\begin{array}{l}\text { Age } \\
<65 \text { years } \\
\geq 65 \text { years }\end{array}$ & $\begin{array}{c}116 \\
98\end{array}$ & $\begin{array}{l}54 \% \\
46 \%\end{array}$ \\
\hline $\begin{array}{l}\text { Sex } \\
\text { Male } \\
\text { Female }\end{array}$ & $\begin{array}{c}154 \\
60\end{array}$ & $\begin{array}{l}72 \% \\
28 \%\end{array}$ \\
\hline $\begin{array}{l}\text { Type of surgery } \\
\text { Subtotal gastrectomy } \\
\text { Total gastrectomy }\end{array}$ & $\begin{array}{c}84 \\
130\end{array}$ & $\begin{array}{l}39.2 \% \\
61.8 \%\end{array}$ \\
\hline $\begin{array}{l}\text { Type of dissection } \\
\text { D1 } \\
\text { D2 }\end{array}$ & $\begin{array}{c}47 \\
167\end{array}$ & $\begin{array}{c}21.9 \% \\
78 \%\end{array}$ \\
\hline $\mathrm{N}$ examined nodes & $\begin{array}{r}\text { Mean }=21 \\
<16 \text { nodes }(8 \\
>16 \text { nodes }(13 \\
<10 \text { nodes }(2\end{array}$ & $\begin{array}{l}\text { des. } \\
\text { tients) } \\
\text { tients) } \\
\text { tients) }\end{array}$ \\
\hline $\begin{array}{l}\text { Resection edge } \\
\text { R0 } \\
\text { R1 } \\
\text { R2 }\end{array}$ & $\begin{array}{c}203 \\
10 \\
1\end{array}$ & $\begin{array}{c}93.9 \% \\
4.6 \% \\
0.5 \%\end{array}$ \\
\hline $\begin{array}{l}\text { Chemotherapy schedule } \\
5 \text { FU } \\
\text { Capecitabine } \\
\text { Cisplatin } \\
\text { No chemotherapy }\end{array}$ & $\begin{array}{c}67 \\
129 \\
3 \\
15\end{array}$ & $\begin{array}{c}31.3 \% \\
60.2 \% \\
1.4 \% \\
7 \%\end{array}$ \\
\hline $\begin{array}{l}\text { Type of radiotherapy } \\
\text { WAI* } \\
\text { Bed }+ \text { nodes }\end{array}$ & $\begin{array}{c}69 \\
145\end{array}$ & $\begin{array}{l}32.2 \% \\
67.8 \%\end{array}$ \\
\hline $\begin{array}{l}\text { Signet-ring cells } \\
\text { Yes } \\
\text { No }\end{array}$ & $\begin{array}{c}44 \\
170\end{array}$ & $\begin{array}{l}20.5 \% \\
79.5 \%\end{array}$ \\
\hline $\begin{array}{l}\text { Time from surgery to RT/CT start } \\
<8 \text { weeks } \\
>8 \text { weeks }\end{array}$ & $\begin{array}{l}102 \\
112\end{array}$ & $\begin{array}{l}47.6 \% . \\
52.4 \%\end{array}$ \\
\hline
\end{tabular}

*WAI: total abdomen irradiation.

$\mathrm{RC} / \mathrm{CT}$ : radiochemotherapy 
In univariate analysis, of the factors explored, those with a poor prognosis that significantly affected survival were the number of lymph nodes involved $(p=0.000)$, aged $\geq 65$ years $(p=0.001)$ and tumour stage $(p=0.022)$. Overall 5 -year survival according to nodal stage was $61.2 \%$ in No, $54.5 \%$ in $\mathrm{pN} 1,37.3 \%$ in $\mathrm{pN} 2,26 \%$ in $\mathrm{pN} 3 \mathrm{a}$ and $28 \%$ in pN3b patients $(p=0.00)$. Overall 5 -year survival was $50 \%$ for patients aged $<65$ years and $29.9 \%$ for those aged $\geq 65$ years. Overall 5 -year survival according to stage was $58 \%$ for pT $1,45.8 \%$ for pT $2,50 \%$ for pT3 and $35.3 \%$ for pT4a.

In multivariate analysis, the factor with a poor prognosis for overall survival was the number of lymph nodes involved, with a HR of 1.40 for each increased N stage $(p=0.00)$, with a HR of 1.78 for those aged 65 years $(p=0.00)$ and a HR of 1.35 for those with more advanced tumour stages $(p=0.01$ ) (Table 3$)$.

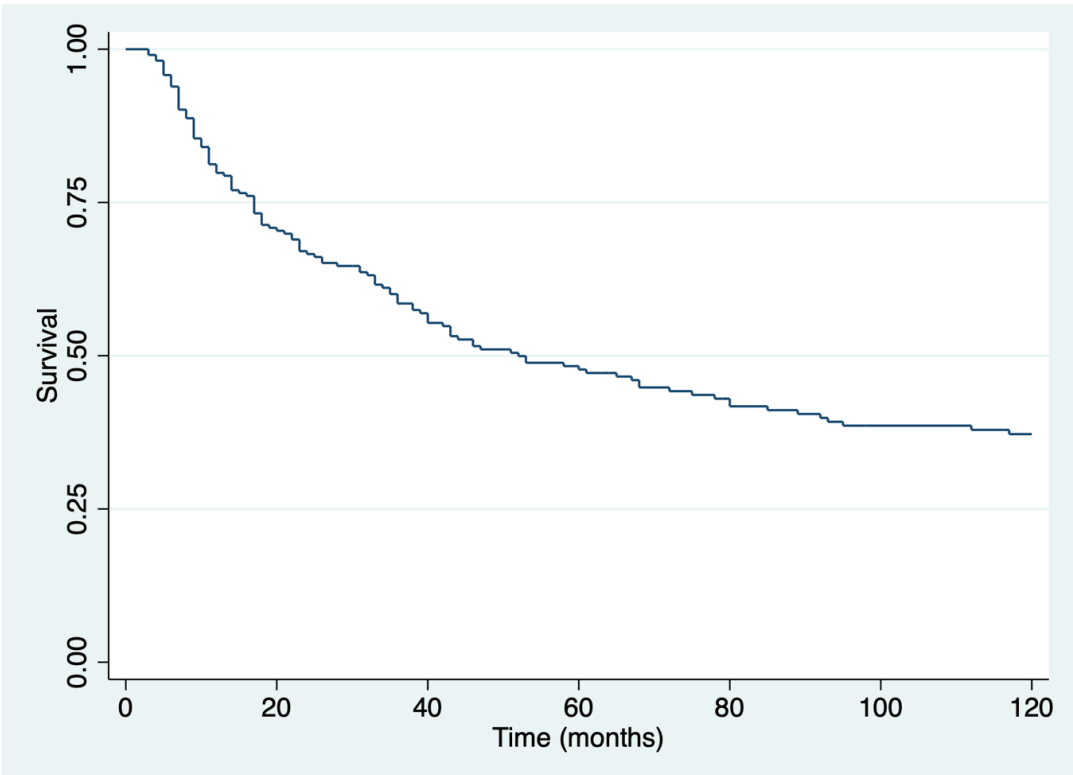

Figure 1. Overall survival (time in months) for all patients.

Table 3. Multivariate analysis of factors influencing OS for all patients.

\begin{tabular}{|l|c|c|}
\hline & HR & $p$-value \\
\hline N nodes involved & 1.40 & 0.00 \\
\hline Age ( $\geq 65$ years) & 1.78 & 0.00 \\
\hline Time from surgery to RT/CT start & 1.07 & 0.68 \\
\hline Chemotherapy & 1.09 & 0.12 \\
\hline R edges & 1.10 & 0.76 \\
\hline Signet-ring cells & 0.96 & 0.68 \\
\hline Tumour stage & 1.35 & 0.01 \\
\hline Type of nodal dissection & 1.10 & 0.63 \\
\hline Type of surgery & 1.07 & 0.65 \\
\hline Type of radiotherapy & 0.81 & 0.24 \\
\hline Sex & 1.41 & 0.08 \\
\hline
\end{tabular}




\section{Discussion}

Extended D2 surgery in gastric cancer achieves survival rates of less than $50 \%$ at 5 years [9]. In the best series, survival is around $30 \%-40 \%$ when there are advanced locoregional compromise factors [10].

Regarding the national literature, there are some data published with exclusive surgery, with similar results [18, 19].

In 2001, the pivotal US Intergroup trial 01164 first reported the results of postoperative radiochemotherapy versus surgery alone establishing postoperative radiochemotherapy in addition to surgery as the standard treatment for gastric cancer. This regimen was shown to improve both locoregional control and overall survival compared to surgery alone in medically fit patients who had microscopically radical resection [6]. A subsequent publication with a 10-year follow-up confirmed the results of the first publication, with an absolute benefit in overall survival (OS) of $9 \%$, with a 1.32 hazard ratio (HR) (95\% Cl: 1.1-1.6; $p=0.0046)$. Relapse-free survival (RFS) was $11 \%$ with an HR of 1.51 (95\% Cl: 1.25-1.83; $p$ 0.001) [11]. No late toxicity was reported during the long-term follow-up.

Regarding perioperative chemotherapy alone, without the addition of Radiotherapy, in 2006, Cunningham et al [12] showed that chemotherapy with epirubicin, cisplatin and 5-FU for six cycles, three administered pre-operatively and three post-operatively, was associated with tumour shrinkage, tumour downstaging and significant overall-survival benefit compared to surgery alone. With a median follow-up of 4 years, the perioperative chemotherapy group had a higher probability of overall survival ( $\mathrm{HR}: 0.75,95 \% \mathrm{Cl}, 0.60-0.93, p=0.009)$ and a better survival rate at five years, $36 \%$ compared to $23 \%$ in the surgery group. Thirty-six patients in the perioperative chemotherapy group (14.4\%) presented local recurrence versus 52 patients $(20.6 \%)$ in the surgery group, indicating a lack of locoregional control. Finally, the protocol could only be completed by $42 \%$ of the patients assigned to chemotherapy. Therefore, after three cycles of chemotherapy after gastrectomy, compliance is greatly reduced. Its long-term publication is still pending for mature results.

The FLOT4 study evaluated two regimens of perioperative chemotherapy, demonstrating a better median survival with the FLOT versus ECF/ECX regimens (50 versus 35 months), against high toxicity, with 14 more patients alive at 36 months; however, the ECF arm included 11 more $\mathrm{N}+$ patients. Data with longer follow-up from this study are still missing to determine if it is appropriate to abandon the ECF regimen altogether [13].

Regarding adjuvant chemotherapy, the CLASSIC trial randomised 1,035 patients to D2 gastrectomy with or without 6 months of adjuvant chemotherapy. After a median follow-up of 62.4 months, it reported beneficial results in overall survival in the adjuvant-treatment arm; however, only $66.5 \%$ of patients were able to complete treatment, against grades 3-4 toxicity in $56 \%$ of them, resulting highly toxic [14].

At the same time, Kang et al [16] published the ARTIST study [15], with an update in 2015 after 7 years of follow-up. In the latter trial, 458 patients with gastric cancer were randomised to chemotherapy (six cycles of capecitabine) or radiochemotherapy (two cycles of chemotherapy with capecitabine plus radiotherapy - 45 Gy in 25 sessions - plus two cycles of chemotherapy) after D2 resection. After a minimum follow-up of 5 years, 77 patients (33.8\%) in the chemotherapy arm and 60 (26.1\%) in the radiochemotherapy arm experienced recurrence. Locoregional failure was $9.6 \%$ (29 patients in the chemotherapy and 15 in the radiochemotherapy arms; $p=0.03$ ); in patients with compromised nodes, radiochemotherapy significantly decreased locoregional recurrence compared to chemotherapy $(14.5 \%$ versus $6.4 \%, p=$ 0.009). After 7 years of follow-up, subgroup analysis confirms again that radiochemotherapy significantly improves disease-free survival in patients with lymph node involvement and with intestinal histotype [16].

In 2018, the CRITICS study [17] was published, in which 788 patients with stage IB-IVA resectable gastric or gastroesophageal adenocarcinoma were enrolled. Patients were randomised to neoadjuvant and adjuvant chemotherapy $(n=393)$ or neoadjuvant chemotherapy followed by postoperative radiochemotherapy $(n=395)$. After surgery, $233 / 393$ patients $(59 \%)$ started chemotherapy and $245 / 395(62 \%)$ started radiochemotherapy. After a median follow-up of 61.4 months, there was no statistically significant difference regarding overall survival ( $p=0.90$ ). During postoperative treatment, chemotherapy resulted in higher toxicity and lower treatment compliance than radiochemotherapy. Grades 3-4 acute toxicity was $48 \%$ and $9 \%$ in the chemotherapy group, respectively, and $41 \%$ and $4 \%$ in the radiochemotherapy group, respectively. The worst toxicity was neutropenia, which occurred more frequently in the chemotherapy arm (34\%) versus the radiotherapy arm (4\%).

Recently, the interim results of ARTIST 2 have been published. This early report concluded that in patients with curatively D2-resected, stage II/III, node-positive GC, adjuvant SOX (S-1 plus oxaliplatin) or SOXRT (S-1 plus oxaliplatin plus chemoradiotherapy) was effective in prolonging DFS, when compared to S-1 monotherapy [29]. When analysing the toxicities of each scheme, peripheral neuropathy, which may be irreversible, 
occurs in a greater percentage with the SOX scheme than that with the scheme that includes radiochemotherapy; therefore, it continues to be the standard for our institution.

Regarding publications of clinical-practice results of treatments with adjuvant or neoadjuvant therapies in Chile, the published experience comes exclusively from experiences with adjuvant radiochemotherapy from different reference cancer centres (PUC-INC-IRAM-FALP), with global 5-year survival rates varying between 37.5\% and 54\% [20-24], similar to those reported in randomised studies.

To date, there are no published data on local clinical practice results with chemotherapy alone, either as an adjuvant or as a perioperative treatment.

The efficacy of adjuvant therapy with radiochemotherapy and/or perioperative chemotherapy is well established with level-1 evidence; however, this should not be confused with the effectiveness of the therapy. Efficacy is understood as the benefit achieved in clinical studies with well-defined, selected patients; however, effectiveness is the benefit in the real world, outside of clinical studies.

In gastric cancer treatment, as in other tumours, there are data available that allow us to conclude that only radiochemotherapy has shown to have both efficacy and effectiveness, in contrast to perioperative chemotherapy, which has only been shown to have efficacy, although its effectiveness is unknown [25-26].

Furthermore, in local clinical practice, if only adjuvant or perioperative chemotherapy is performed, it should be clear that it is necessary to perform a microsatellite instability (MSI) study since chemotherapy worsens prognosis in cases with MSI [27, 28].

Taking into account the global increase in the incidence of this disease and the recently-described evidence, it is essential to know the oncologic results with other regimens in daily practice and, thus, to be able to estimate the impact of adjuvant treatments in our country.

Our retrospective series is the largest one published in our country, with results similar to those described in different international randomised and retrospective studies, which supports the use of adjuvant radiochemotherapy in our institution and country.

\section{Conclusion}

In operated patients with locoregionally advanced gastric cancer treated with adjuvant radiochemotherapy with curative intent, 5-year overall survival reported from local clinical practice is similar to that reported in randomised series and supports its use as an effective treatment for this type of patients in our country.

\section{Funding statement}

We did not receive any financial support.

\section{Conflicts of interest}

The authors declare no conflict of interest.

\section{References}

1. Bray F, Ferlay J, and Soerjomatarm I, et al (2018) Global cancer statistics 2018: GLOBOCAN estimates of incidence and mortality worldwide for 36 cancers in 185 countries CA Cancer J Clin 68(6) 394-424 https://doi.org/10.3322/caac.21492 PMID: 30207593

2. Subsecretaría de Salud Pública (2014) Guías Clínicas AUGE 2014. Cáncer gástrico (Chile: Ministerio de Salud) https://www.minsal.cl/sites/ default/files/files/GPC\%20G\%C3\%A1strico\%20(PL).pdf 
3. Plan Nacional De Cáncer 2018-2028 (2018) https://cdn.digital.gob.cl/filer_public/d3/0a/d30a1f5e-53d9-4a31-a4fe-e90d8d9a2348/ documento_plan_nacional_de_cancer.pdf

4. Amin MB, Edge S, and Greene F, et al (2017) AJCC Cancer Staging Manual 8th edn (New York: Springer International Publishing)

5. Csendes A and Figueroa M (2017) Situación del cáncer gástrico en el mundo y en Chile Rev Chil Cir 69(6) 502-507 https://doi. org/10.1016/j.rchic.2016.10.014

6. Macdonald JS, Smalley SR, and Benedetti J, et al (2001) Chemoradiotherapy after surgery compared with surgery alone for adenocarcinoma of the stomach or gastroesophageal junction N Engl J Med 345 725-730 https://doi.org/10.1056/NEJMoa010187 PMID: 11547741

7. Howlader N, Noone AM, and Krapcho M, et al (eds) SEER Cancer Statistics Review, 1975-2017 (Bethesda: National Cancer Institute) https://seer.cancer.gov/csr/1975_2017/

8. González-Domingo M, Baeza M, and Giannini O (2010) Adjuvant treatment of locally advanced gastric cancer completely resected. A phase III study: total abdominal irradiation with concomitant chemotherapy or extended nodal (RATONES) with concomitant chemotherapy Radiother Oncol 96(suppl 1) s15-s16 https://doi.org/10.1016/S0167-8140(10)80022-2

9. García CC (2013) Actualización del diagnóstico y tratamiento del cáncer gástrico Rev med clin Condes 24(4) 627-636 https://doi. org/10.1016/S0716-8640(13)70201-3

10. Fuchs CS and Mayer RJ (1995) Gastric carcinoma N Engl J Med 333(1) 32-41 https://doi.org/10.1056/NEJM199507063330107 PMID: 7776992

11. Smalley SR, Benedetti JK, and Haller DG, et al (2012) Updated analysis of SWOG-directed intergroup study 0116: a phase III trial of adjuvant radiochemotherapy versus observation after curative gastric cancer resection J Clin Oncol $302327-2333$ https://doi. org/10.1200/JCO.2011.36.7136 PMID: 22585691 PMCID: 4517071

12. Cunningham D, Allum WH, and Stenning SP, et al (2006) Perioperative chemotherapy versus surgery alone for resectable gastroesophageal cancer N Engl J Med 355 11-20 https://doi.org/10.1056/NEJMoa055531 PMID: 16822992

13. Al-Batran SE, Homann N, and Pauligk C, et al (2019) Perioperative chemotherapy with fluorouracil plus leucovorin, oxaliplatin, and docetaxel versus fluorouracil or capecitabine plus cisplatin and epirubicin for locally advanced, resectable gastric or gastro-oesophageal junction adenocarcinoma (FLOT4): a randomised, phase 2/3 trial Lancet 393(10184) 1948-1957 https://doi.org/10.1016/S01406736(18)32557-1 PMID: 30982686

14. Noh SH, Park SR, and Yang HK, et al (2014) Adjuvant capecitabine plus oxaliplatin for gastric cancer after D2 gastrectomy (CLASSIC): 5-year follow-up of an open-label, randomized phase 3 trial Lancet Oncol 15(12) 1389-1396 https://doi.org/10.1016/S14702045(14)70473-5 PMID: 25439693

15. Lee J, Lim DH, and Kim S, et al (2012) Phase III trial comparing capecitabine plus cisplatin versus capecitabine plus cisplatin with concurrent capecitabine radiotherapy in completely resected gastric cancer with D2 lymph node dissection: the ARTIST trial J Clin Oncol 30(3) 268-273 https://doi.org/10.1200/JCO.2011.39.1953

16. Park SH, Sohn TS, and Lee J, et al (2015) Phase III trial to compare adjuvant chemotherapy with capecitabine and cisplatin versus concurrent chemoradiotherapy in gastric cancer: final report of the adjuvant chemoradiotherapy in stomach tumors trial, including survival and subset analyses J Clin Oncol 33(28) 3130-3136 https://doi.org/10.1200/JCO.2014.58.3930 PMID: 25559811

17. Cats A, Jansen EPM, and van Grieken NCT, et al (2018) Chemotherapy versus chemoradiotherapy after surgery and preoperative chemotherapy for resectable gastric cancer (CRITICS): an international, open-label, randomised phase 3 trial Lancet Oncol 19(5) 616-628 https://doi.org/10.1016/S1470-2045(18)30132-3 PMID: 29650363

18. Cenitagoya GF, Bergh CK, and Klinger-Roitman J (1998) A Prospective Study of Gastric Cancer. Real 5-year survival rates and mortality rates in a country with high incidence Dig Surg 15(4) 317-322 https://doi.org/10.1159/000018645 PMID: 9845606 
19. García C, Benavides C, and Apablaza S, et al (2007) Surgical treatment of gastric cancer: results in 423 cases Rev Med Chile 135(6) 687-695

20. Baeza MR, Giannini O, and Rivera R, et al (2001) Adjuvant radiochemotherapy in the treatment of completely resected, locally advanced gastric cancer Int J Radiat Oncol Biol Phys 50(3) 645-650 https://doi.org/10.1016/S0360-3016(01)01467-5 PMID: 11395231

21. Garrido M, Bustos M, and Orellana E, et al (2008) Postoperative radio-chemotherapy in locally advanced gastric cancer Rev Med Chile 136(7) 844-850 PMID: 18949159

22. Muller B, Balbontín P, and Cárcamo M, et al (2009) Results of adjuvant chemoradiation after curative surgery for gastric cancer: a retrospective study Rev Med Chile 137(5) 649-656

23. Isa N, Russo M, and López H (2014) Adjuvant chemoradiotherapy in advanced gastric cancer: experience in 168 patients Rev Med Chile 142 199-203 https://doi.org/10.4067/S0034-98872014000200008

24. Norero E, Bustos M, and Herrera ME, et al (2016) Postoperative adjuvant treatment for gastric cancer improves long-term survival after curative resection and D2 lymphadenectomy. Results from a Latin American Center Eur J Surg Oncol 42(1) 94-102 https://doi. org/10.1016/j.ejso.2015.10.003

25. Templeton AJ, Vera-Badillo F, and Wang L, et al (2013) Translating clinical trials to clinical practice: outcomes of men with metastatic castration resistant prostate cancer treated with docetaxel and prednisone in and out of clinical trials Ann Oncol 24 2972-2977 https:// doi.org/10.1093/annonc/mdt397 PMID: 24126362

26. Kozak K and Moody J (2008) The survival impact of the intergroup 0116 trial on patients with gastric cancer Int J Radiat Oncol Biol Phys 72(2) 517-521 https://doi.org/10.1016/j.ijrobp.2007.12.029 PMID: 18249500

27. Choi YY, Kim H, and Shin SJ, et al (2019) Microsatellite instability and programmed cell death-ligand 1 expression in stage II/III gastric cancer: post hoc analysis of the CLASSIC randomized controlled study Ann Surg 270(2) 309-316 https://doi.org/10.1097/ SLA.0000000000002803

28. Smyth EC, Wotherspoon A, and Peckitt C, et al (2017) Mis-match repair deficiency, microsatellite instability, and survival: an exploratory analysis of the Medical Research Council Adjuvant Gastric Infusional Chemotherapy (MAGIC) trial JAMA Oncol 3 1197-1203. https://doi.org/10.1001/jamaoncol.2016.6762 PMID: 28241187 PMCID: $\underline{5824280}$

29. Park SH, Zang DY, and Han B, et al (2019) ARTIST 2: Interim results of a phase III trial involving adjuvant chemotherapy and/or chemoradiotherapy after D2-gastrectomy in stage II/III gastric cancer (GC) J Clin Oncol 37(15_suppl) 4001-4001 https://doi.org/10.1200/ JCO.2019.37.15_suppl.4001 